\title{
Self-Reported Social Media Use among Ophthalmology Residents
}

\author{
Arjun Watane, MD ${ }^{1,2}$ Hasenin Al-khersan, MD ${ }^{1}$ Meghana Kalavar, MD ${ }^{1,3}$ Bilal Ahmed, MD \\ Michael Venincasa, $\mathrm{MD}^{1}$ Jayanth Sridhar, $\mathrm{MD}^{1}$
}

${ }^{1}$ Bascom Palmer Eye Institute, Department of Ophthalmology, University of Miami Miller School of Medicine, Miami, Florida

2 Department of Ophthalmology and Visual Science, Yale School of

Address for correspondence Jayanth Sridhar, MD, 900 NW 17th Street, Miami, FL 33136 (e-mail: jsridhar1@med.miami.edu).

Medicine, New Haven, Connecticut

${ }^{3}$ Department of Ophthalmology and Visual Science, Ohio State

University Havener Eye Institute, Columbus, Ohio

${ }^{4}$ Department of Ophthalmology, University of lowa, lowa City, lowa

J Acad Ophthalmol 2021;13:e195-e199.

\begin{abstract}
Objective To assess ophthalmology trainees' self-reported use of and attitudes toward social media.

Methods An online survey was distributed by email to ophthalmology residency applicants of the Bascom Palmer Eye Institute between September 2016 and January 2020.

Results Of the 1,688 email recipients, the survey was filled by 208 ophthalmology trainees $(12.3 \%)$. Nearly all trainees reported using social media for personal purposes (92.3\%), while less than half used social media for professional purposes (43.4\%). There were mixed sentiments regarding the impact of social media on the patient-physician relationship, with the majority feeling that it challenges a physician's authority (55.2\%) but also empowers the patient (57.5\%) and encourages shared care (92.8\%). Twentyfive percent of trainees had reviewed professional social media guidelines, and most rated the quality of medical information on social media as "poor" (60.9\%). There were low rates of trainees looking up patients (13.8\%), providing their account information to patients $(1.5 \%)$, responding to patients' messages (2.6\%), following patients' accounts (2.6\%), and being followed by patients (2.6\%).

Keywords

- social media

- ophthalmology

- residency

Conclusion The majority of ophthalmology trainees are active on social media. As these trainees enter practice, ophthalmology will likely see a rise in social media use. Training programs should consider a formal social media policy that is shared with all trainees as part of their education.
\end{abstract}

As a pillar of communication in contemporary society, social media has found a strong footing in medicine. From networking with colleagues and disseminating knowledge, to building professional recognition and communicating with patients, an individual's online presence may greatly affect her/his career trajectory. ${ }^{1-5}$ Especially on Twitter (Twitter, Inc., San Francisco, CA), the medical community is burgeoning with students, trainees, educators, and healthcare received

March 17, 2021

accepted after revision

July 26, 2021
DOI https://doi.org/ $10.1055 / \mathrm{s}-0041-1736661$. ISSN 2475-4757.

\footnotetext{
(C) 2021. The Author(s).

This is an open access article published by Thieme under the terms of the Creative Commons Attribution-NonDerivative-NonCommercial-License, permitting copying and reproduction so long as the original work is given appropriate credit. Contents may not be used for commercial purposes, or adapted, remixed, transformed or built upon. (https://creativecommons.org/ licenses/by-nc-nd/4.0/)

Thieme Medical Publishers, Inc., 333 Seventh Avenue, 18th Floor, New York, NY 10001, USA
} 
workers participating through the use of the hashtag "\#medtwitter." This community has surged during the COVID-19 pandemic, as education and networking were shifted primarily online. ${ }^{6}$

While social media may benefit medical professionals and trainees, there are also concerns regarding patient confidentiality, repercussions for subjective "unprofessional" behavior, as well as a risk for Social Media Disorder (SMD). ${ }^{7}$ SMD is characterized by social media addiction and may be associated with resident stress and burnout. ${ }^{8}$ Recently, a scale was developed to help identify adolescents at risk of SMD. ${ }^{9}$ Further, few formalized curricula regarding the professional use of social media exist within training programs.

The present study aims to assess ophthalmology trainee attitudes toward and use of social media. We characterize if, why, and how ophthalmology trainees are incorporating social media in their training and identify the prevalence of SMD in this population.

\section{Methods}

Institutional review board approval was obtained from the University of Miami and this study adhered to the Declarations of Helsinki. A survey assessing role and attitudes toward social media and prevalence of SMD based on the validated 9-item Social Media Disorder Scale was distributed to a listserv of ophthalmology residency applicants to the Bascom Palmer Eye Institute between September 2016 and January 2020. ${ }^{9}$ The survey included consent prior to being filled, and responses were collected between October 25, 2020, and November 8, 2020.

Demographic information collected included age, gender, and level of training. Participants were asked if they used social media for personal and professional purposes. Personal use was defined as interacting with friends and family for non-work-related reasons. Professional use was defined as the use of social media in a work-related capacity such as to interact with patients, increase practice visibility, and communicate with colleagues regarding work or other ophthalmology matters. A diagnosis of SMD was made when five or more out of the nine criteria on the SMD scale were met in accordance with the accepted definition (preoccupation, tolerance, withdrawal, persistence, escape, problems, deception, displacement, and conflict). ${ }^{9}$ Chi-square analyses were used for the analysis of social media use in ophthalmology trainees compared with that in practicing ophthalmologists, which was previously examined in a study by one of the authors (HA). ${ }^{10}$

\section{Results}

Of the 1,688 email recipients, 208 (12.3\%) ophthalmology trainees replied to the survey through the email link. Eightyeight (42.3\%) respondents were identified as female, 119 (57.2\%) identified as male, and $1(0.5 \%)$ respondent selected "other" for gender identity. The average age of all respondents was 29.7 (SD: 3.4; range: 24-58) years. Of all respondents, 54 (25.9\%) were in post-graduate year (PGY) one, 43

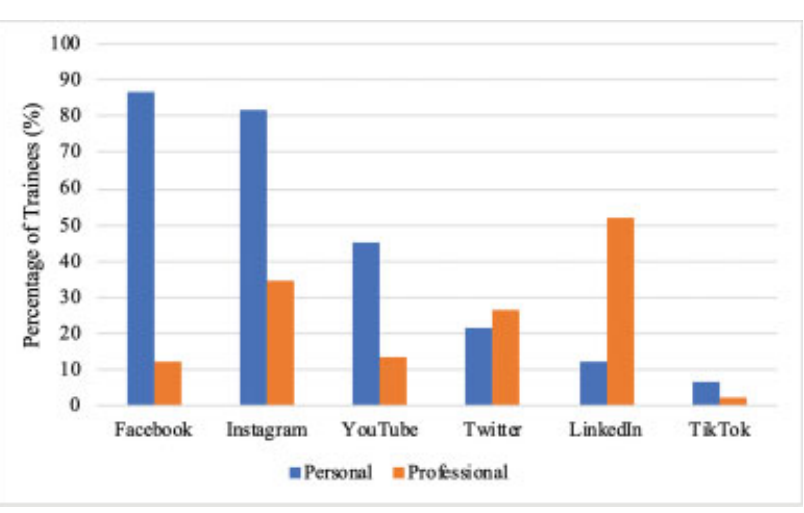

Fig. 1 The percentage of trainees using different social media platforms for professional and personal reasons.

(20.7\%) were in PGY-2, 51 (24.5\%) were in PGY-3, 56 (26.9\%) were in PGY-4, 3 (1.4\%) were in PGY-5, and 1 (0.5\%) was in PGY-6.

Of the 208 respondents, 192 (92.3\%) trainees use social media for personal purposes. The top three platforms used for personal use were Facebook (166, 86.4\%), Instagram (157, $81.8 \%)$, and YouTube $(87,45.3 \%)$. There were $90(43.4 \%)$ trainees who used social media for professional reasons. The top three platforms for professional use were LinkedIn (47, 52.2\%), Instagram (31, 34.4\%), and Twitter (24, 26.7\%) (-Fig. 1).

Comparison of the proportion of ophthalmology trainees on social media to that of practicing ophthalmologists (from a study by Al-Khersan et $\mathrm{al}^{10}$ ) revealed that the proportion of trainees on social media for personal purposes (92.3\%) was significantly higher than the proportion of attending physicians using social media for personal purposes $(68.3 \%$, $p<0.001)$. In contrast, the proportion of trainees using social media for professional purposes (43.4\%) was not significantly different from the proportion of attending physicians using social media for professional purposes $(45.2 \%, p=0.73)$.

Survey responses are presented in - Table 1. Two respondents met full criteria (met at least 5 criteria) for SMD, and 12 were at risk (met at least 3 criteria) for SMD according to the SMD scale (-Table 2 ).

\section{Discussion}

The present study is the first to assess the use of social media among ophthalmology trainees and demonstrates its widespread use in both personal and professional capacities. Our finding that trainees are utilizing social media personal accounts more often than attendings is in line with previous trends. A prior study of ophthalmologists' tweets at annual meetings of the American Academy of Ophthalmology found that the majority were still in-training or in practice for less than 10 years. ${ }^{11}$ In contrast, there was no significant difference in the rates of professional social media use between trainees and attending ophthalmologists. ${ }^{10}$ Many professional accounts are often run by social media managers or by the institutions employing ophthalmologists, which may influence this finding. ${ }^{10}$ Additionally, the perceived 
Table 1 Survey questions

\begin{tabular}{|c|c|}
\hline & Yes \\
\hline Have separate professional and personal social media accounts. $(n=208)$ & $27(13 \%)$ \\
\hline Feel it is important to have a professional social media presence. $(n=207)$ & $81(39.1 \%)$ \\
\hline Are aware of professional social media guidelines. $(n=208)$ & $98(47.1 \%)$ \\
\hline Have reviewed professional social media guidelines. $(n=208)$ & $53(25.5 \%)$ \\
\hline $\begin{array}{l}\text { Have received instructions from their institution/department } \\
\text { regarding social media use. }(n=208)\end{array}$ & $98(47.1 \%)$ \\
\hline Are encouraged by their institution to use social media. $(n=206)$ & $68(33.0 \%)$ \\
\hline Believe social media may challenge a physician's authority. $(n=194)$ & $107(55.2 \%)$ \\
\hline Believe social media empowers the patient. $(n=193)$ & $111(57.5 \%)$ \\
\hline Believe that social media encourages shared care. $(n=193)$ & $90(92.8 \%)$ \\
\hline Rate the quality of medical information on social media as "poor" $(n=192)$ & $117(60.9 \%)$ \\
\hline Rate the quality of medical information on social media as "acceptable" $(n=192)$ & $68(35.4 \%)$ \\
\hline Rate the quality of medical information on social media as "good” $(n=192)$ & $7(3.6 \%)$ \\
\hline Have looked up a patient on social media. $(n=195)$ & $27(13.8 \%)$ \\
\hline Have provided their social media account to a patient. $(n=195)$ & $3(1.5 \%)$ \\
\hline Have responded to patient messages on social media. $(n=195)$ & $5(2.6 \%)$ \\
\hline Have followed a patient on social media. $(n=195)$ & $5(2.6 \%)$ \\
\hline Have had a patient follow them on social media. $(n=195)$ & $20(10.3 \%)$ \\
\hline Social media has positively impacted their training. $(n=191)$ & $101(52.9 \%)$ \\
\hline Social media has allowed networking with other health professionals. $(n=194)$ & $124(63.9 \%)$ \\
\hline Social media has helped find research projects. $(n=194)$ & $14(7.2 \%)$ \\
\hline
\end{tabular}

Table 2 Criteria for social media disorder ${ }^{9}$ during the past year, have you...

\begin{tabular}{|l|l|}
\hline & Yes (n=194) \\
\hline $\begin{array}{l}\text { regularly found that you can't think of anything else but the moment that you will be able to use } \\
\text { social media again? }\end{array}$ & $7(3.6 \%)$ \\
\hline regularly felt dissatisfied because you wanted to spend more time on social media? & $3(1.5 \%)$ \\
\hline often felt bad when you could not use social media? & $7(3.6 \%)$ \\
\hline tried to spend less time on social media, but failed? & $73(37.6 \%)$ \\
\hline regularly neglected other activities (e.g., hobbies, sports) because you wanted to use social media? & $16(8.2 \%)$ \\
\hline regularly had arguments with others because of your social media use? & $6(3.1 \%)$ \\
\hline regularly lied to your parents or friends about the amount of time you spend on social media? & $2(1.0 \%)$ \\
\hline often used social media to escape from negative feelings? & $42(21.6 \%)$ \\
\hline had serious conflict with your parents, brother(s) or sister(s) because of your social media use? & $1(0.5 \%)$ \\
\hline
\end{tabular}

incentives for maintaining a strictly professional page as a trainee may not be as compelling as for practicing ophthalmologists who may benefit in building their practices and reputation. Lastly, an interesting question for future research is whether current trainees believe in separating their "personal" and "professional" pages or whether they prefer to blend the two. The strong personal social media use by trainees may be suggestive of increased professional use as they graduate and begin practicing. Another avenue for the study is if the preferred platforms for personal and profes- sional pages change with time and/or professional development.

Social media may offer benefits to trainees, as it reportedly has positively impacted their training, provided avenues for networking, and helped them find research opportunities. There are also risks to consider in the sphere of patient privacy and professionalism. In this study, there were low rates of professional social media guideline awareness and knowledge, as well as sparse education and encouragement by institutions regarding social media use. A clear understanding of social 
media rules is imperative, given the potential negative consequences, namely patient privacy breaches and subjective "unprofessional" behavior. We encourage training programs to address this discrepancy between social media use by trainees and guideline awareness by developing social media policy and educating trainees on social media guidelines set forth by professional associations, including the American Academy of Ophthalmology (AAO). ${ }^{12,13}$ In short, the AAO's guidelines are as follows: identify yourself and your qualifications; identify why you are offering information and how it is substantiated; be trustworthy, honest, and reliable; provide knowledge and information that is useful and desirable; and share appropriately. ${ }^{13}$

We also explored the attitudes of trainees toward the role of social media in patient-physician interactions and found a mixed sentiment. The majority agreed that social media encourages shared care between healthcare providers. Previous studies have reported the use of social media to increase patient referrals and professional visibility. ${ }^{10,14-17}$ Additionally, more than half of trainees believed that social media empowers the patient. While this does allow patients to be more engaged in their healthcare experience, a concern shared by many trainees was that social media may challenge a physician's authority. These ethical implications have been previously reported, and further research is needed to understand the role of social media in patient-physician relationships. ${ }^{18}$

The rate of actual social media interaction between patients and ophthalmology trainees was minimal, with only a minority of trainees looking up, being followed by, providing account information, responding to patient messages, or following their patients. Potential reasons for this low rate of interaction may be greater adherence by trainees to traditional patientphysician boundaries compared to practicing physicians who have formed lifelong relationships with their patients, some of which may go beyond a strictly professional relationship and brush ethical boundaries. Another reason could be that trainees are generally not actively involved in patient recruitment, which is a common motive for practicing physicians to utilize social media. ${ }^{10,15-17}$ These results suggest that ophthalmology trainees prefer using social media as a networking and educational tool over using it as a medium for current and prospective patient interaction.

Although previous studies have evaluated the prevalence of SMD in other specialties, this is the first study to evaluate its prevalence in ophthalmology. ${ }^{8}$ Given that most ophthalmology trainees utilize social media, it may be concerning that 1 in 15 ophthalmologists in-training are at risk for or have SMD. In comparison, a survey of urology trainees found that 1 in 10 urologists in-training was at risk for SMD. ${ }^{8} \mathrm{SMD}$ has been suggested to be prominent in individuals as a coping mechanism for loneliness and depression, and it is possible that SMD may contribute to resident stress levels. ${ }^{8,19-21}$ With social media becoming increasingly integrated within ophthalmology, SMD may represent an area where further research is needed to mitigate its risk. We recommend training programs to include information regarding healthy social media practices in their professional development curricula.
Our study shares the general limitations of surveys. First, the data may be influenced by a sampling bias. The survey was distributed electronically, and respondents may have been more likely to use social media than those that did not respond. Furthermore, surveys were emailed only to trainees who had applied for residency at a single academic institution. Additionally, applicants may have applied for residency with their medical school's institutional email address, which may no longer be in use if in residency at a different institution. Finally, the SMD scale was developed on adolescents aged 10 to 17 years and may not be psychometrically valid when applied to adults in their late 20 s or early 30 s. Despite these limitations, the survey provides interesting insights regarding the use of social media by ophthalmology trainees.

Ultimately, the present work demonstrates the widespread use of social media by ophthalmology trainees, both personally and professionally. As these trainees graduate and begin their careers, social media may be more integral to ophthalmology practices and patient-physician interactions in the future. Benefits of social media for trainees include networking, educational, and research opportunities. Training programs should work to increase guideline awareness, promote professionalism and hygiene, institute social media policy, and develop social media curricula to educate trainees regarding their policy.

\section{Funding}

Bascom Palmer Eye Institute received funding from the NIH Core Grant P30EY014801, Department of Defense Grant \#W81XWH-13-1-0048, and a Research to Prevent Blindness Unrestricted Grant. The sponsors or funding organizations had no role in the design or conduct of this research.

\section{Conflict of Interest}

Dr. Sridhar is a consultant for Alcon, Dorc, Regeneron, and Oxurion. None of the other authors have any conflicts to disclose.

\section{References}

1 Park SSE, Akella SS, Moon JY, et al. Building your brand: analysis of successful oculoplastic surgeons on social media. Ophthal Plast Reconstr Surg 2020;36(06):582-589

2 McGregor F, Somner JE, Bourne RR, Munn-Giddings C, Shah P, Cross V. Social media use by patients with glaucoma: what can we learn? Ophthalmic Physiol Opt 2014;34(01):46-52

3 Fathy C, Cehelyk E, Israilevich R, et al. When ophthalmology goes virtual amid a pandemic: content analysis of the 2020 \#ASCRSVirtualMeeting. J Cataract Refract Surg 2020

4 Mangan MS, Cakir A, Yurttaser Ocak S, Tekcan H, Balci S, Ozcelik Kose A. Analysis of the quality, reliability, and popularity of information on strabismus on YouTube. Strabismus 2020;28 (04):175-180

5 Leitão Guerra RL. A perspective on retina education through social media. Int J Retina Vitreous 2020;6:44

6 O'Glasser AY, Jaffe RC, Brooks M. To tweet or not to tweet, that is the question. Semin Nephrol 2020;40(03):249-263

7 Tsui E, Rao RC. Navigating social media in \#ophthalmology. Ophthalmology 2019;126(06):779-782 
8 Dubin JM, Greer AB, Patel P, et al. Global survey of the roles and attitudes toward social media platforms amongst urology trainees. Urology 2021;147:64-67

9 van den Eijnden RJJM, Lemmens JS, Valkenburg PM. The Social Media Disorder Scale. Comput Human Behav 2016;61:478-487

10 Al-Khersan H, Lazzarini TA, Fan KC, et al. Social media in ophthalmology: an analysis of use in the professional sphere. Health Informatics J 2020;26(04):2967-2975

11 Christiansen SM, Oetting TA, Herz NL, et al. Twitter at the 2014 and 2015 Annual Meetings of the American Academy of Ophthalmology. Ophthalmology 2016;123(08):1835-1837

12 DeCamp M. Social media and medical professionalism: toward an expanded program. Arch Intern Med 2012;172(18):1418-1419

13 American Academy of Ophthalmology. Advisory opinion - social media and professionalism. 2018. Accessed August 24, 2021 at: https://www.aao.org/ethics-detail/advisory-opinion-social-media-professionalism

14 Wheeler CK, Said H, Prucz R, Rodrich RJ, Mathes DW. Social media in plastic surgery practices: emerging trends in North America. Aesthet Surg J 2011;31(04):435-441
15 Kaufman LB. Use social media to market your practice. Information Technology Practice Perfect 2016:47-48

16 Steven M, Christiansen JGC. Top 5 social media platforms for ophthalmologists. 2014. Available at: https://www.aao. org/young-ophthalmologists/yo-info/article/top-5-social-media-platforms-ophthalmologists

17 Jalkiewicz JF. Leverage social media to build your practice. Ophthalmology Management 2019;23:44, 46, 48

18 Caruso Brown AE, Arthur JD, Mutrie LH, Lantos JD. Seeking a second opinion on social media. Pediatrics 2019;144(05): e20190817. Doi: 10.1542/peds.2019-0817

19 Tran EM, Scott IU, Clark MA, Greenberg PB. Resident wellness in US ophthalmic graduate medical education: the resident perspective. JAMA Ophthalmol 2018;136(06):695-701

20 Tran EM, Scott IU, Clark MA, Greenberg PB. Assessing and promoting the wellness of United States ophthalmology residents: a survey of program directors. J Surg Educ 2018;75(01): 95-103

21 Siddiqui N, Hariprasad SM, Tsipursky M. Burnout in ophthalmology. Ophthalmic Surg Lasers Imaging Retina 2020;51(09):480-484 